\title{
JLEET
}

Journal of Language Education and Educational Technology

Volume 6 No. 2, 2021

e-ISSN: 2502-3306

\section{The Focus of Grammar in International Examinations}

\section{Stephenie O. Busbus, John Rey O. Pelila, Lyzel A. Tabag, Aubrae Frances E. Bannawi, Julsen L. Copete, Frances Corrine D. Bonilla}

School of Advanced Studies, Saint Louis University, Baguio City, Philippines

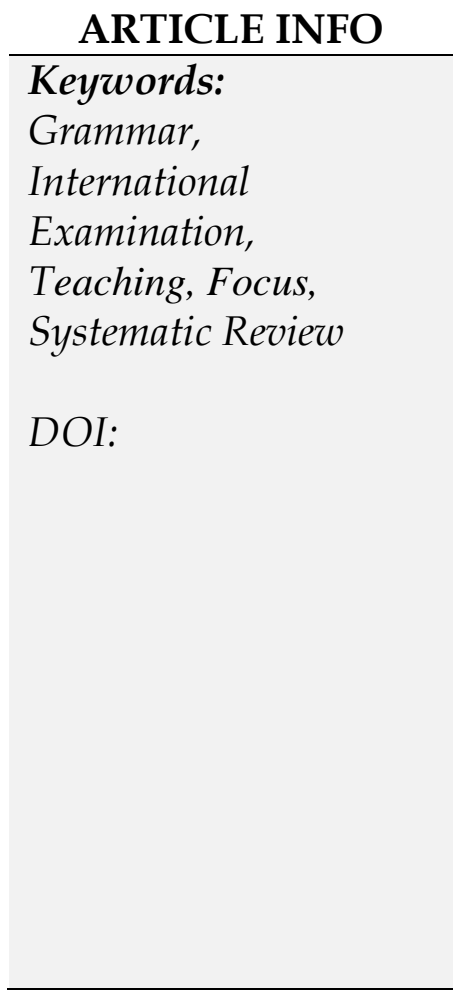

\begin{abstract}
Studies have proven that teaching grammar plays a significant role in teaching of English language. However, there is a need for teachers to know what to focus in teaching grammar because of its complexity in most international examinations. Therefore, the present study aimed at knowing the different focuses in teaching grammar in some of the known international examinations like IELTS, TOEFL, OET, and PTE. The researchers employed a systematic literature review where studies on this area were appraised guided by inclusion-exclusion criteria, and it was found out that there were four (4) primary areas that teachers need to ponder in teaching grammar - syntactic grammar, parts of speech, word choice, and dialect variation. Moreover, it was suggested that teachers need to revisit the practices and approaches they employed in the teaching-learning process of English in general and review all existing English criteria and tools that quantify their content knowledge.
\end{abstract}

\section{INTRODUCTION}

The definition of grammar did not change for the last 50 years. Parkhurst (1963) once said that grammar is the science of the language as it sets forth the rules that govern correct speaking and writing. Similarly, Nordquist (2020) defined it as a study that is systematic, a description of a language, a bound of rules, and examples that deals with syntax and word structures of a language usually intended to aid language learning. 
According to Hawes (2018), most international examinations are designed to test non-native English speakers' proficiency in the language and master English grammar nuances. Besides, these tests measure the knowledge of individuals in the English language focusing on questions that deal with the different macro skills like speaking, reading, and writing. Since the rules in English grammar are crucial to its mastery, concerned individuals must be proficient so that they can have good scores in the examination.

Furthermore, there are indeed features of grammar that are needed to observe and fulfil by learners, especially by test takers based on the different English international examinations like IELTS, TOEFL, OET, PTE, and others.

\subsection{International English Language Testing System (IELTS)}

The International English Language Testing System (IELTS) focuses on grammar range, like on how test takers must have the ability to use different sentence structure and know how to correct grammar errors. This simply means that teachers must teach students not to try and use long, complex sentences all the time if not necessary. On the other hand, accuracy includes correct punctuation, the number of mistakes you make, and how bare the errors are. Common errors in the accuracy could involve mistakes in verb tense, subject/verb agreement, articles, punctuation, complex sentences, modal verbs, and prepositions. Hence, students must note that they must use a broad range of structures, complete accuracy and flexibility, and must only commit minor errors. In terms of speaking, students must remember that as they hesitate, it is more likely related to the content, rather than locating each word or grammar. Yuno Learning (n.d.) supported this by explaining that during the IELTS speaking examinations, the examiner looks for clarity in speech, fluency, spontaneity, good pauses, right stress on the words, pronunciation, and grammatically correct English. If a student's sentence framing is correct while speaking, they will get good points besides many other things like good vocabulary, etc.

\subsection{Test of English as a Foreign Language (TOEFL)}

TOEFL is a requirement in most western countries. The US, in particular, has set the test to ensure students can proceed and succeed in their chosen course in the country where the curriculum is taught in English. The TOEFL test is done online to administer students or applicants outside the country.

According to Mahmud (2014), the success or failure of test takers in taking TOEFL is greatly influenced by various factors like having low motivation, less practice, and insufficient skills in the area that is needed to focus on the said exam. Others also claimed that due to age and social status were also seen as factors. In the study of Hardin (2014), reading difficulties in TOEFL also covers the following - unfamiliar vocabulary, time management, getting caught up in details, and missing keywords.

Moreover, the TOEFL highlights in speaking that test takers must show proficiency in the use of grammar as well as vocabulary. Specifically, they must have a knowledge on how to have a good control of the different structures. This implies that teachers must 
train students to use proper diction and reasonable control in speaking. Also, the said exam is taken by most international students who plan to go abroad for education. It measures non-native English speakers' abilities to use and understand English at the university level. It tests their scope of understanding in English, particularly in reading, speaking, listening, and writing. These are essential skills that one must fulfill to be admitted to the set standard of TOEFL.

\subsection{Occupational English Test (OET)}

OET falls under the category of English for Specific Purposes (ESP). It is designed to meet the healthcare sector's specific needs in 12 healthcare professions: dentistry, dietetics, medicine, nursing, occupational therapy, optometry, pharmacy, physiotherapy, podiatry, radiography, speech pathology, and veterinary science. The test evaluates healthcare professionals' English language competence who have gained their qualifications and training outside an English-speaking country.

It assesses four language skills: writing, speaking, listening, and reading. The speaking and writing sub-tests are tailored to each profession, unlike the listening and reading subtests. While the latter is firmly grounded in the healthcare domain, topics, content, language, and some tasks (e.g., note-taking while listening), they are not as profession-specific as the productive skills tests. The largest groups of test-takers are nurses $(47 \%)$, doctors $(23 \%)$, dentists $(20 \%)$, and pharmacists $(6 \%)$.

Specifically, in this OET exam, test takers need to pay attention to the language itself and the resources of grammar and expression. In language, it mentions that the features that include spelling, punctuation, vocabulary, and grammar/sentence structure must be accurate and not interfere with meaning. The resources of grammar and expression must be rich and flexible, have a wide range of grammar and vocabulary used accurately and flexibly, and be confident in using an idiomatic expression.

\subsection{Pearson Test of English Academic (PTE)}

Pearson Test of English Academic (PTE Academic) computer-based international examination focusing also on assessing English language. It provides a measure of a test taker's language ability to assist education institutions and professional and government organizations that require a standard of academic English language proficiency for admission purposes (Pearson Education, 2019).

Moreover, the PEARSON writing examination assesses the individual's ability to write a concise summary of the assigned topic. The examinee must be able to produce synthesized writing under a timed condition. Note-taking skills are also given points, and they must be achieved under proper contexts and proper grammar. Examples and details are scored as well. There must also be organization, logic, and completeness of ideas. PEARSON speaking assesses similar features of speaking compared with the previous international speaking tests. The test assesses the test takers' ability to identify the purpose and expound on it. There must also be the key elements and proper timing of speech. Proper intonation, pronunciation, and stress are also assessed in the Pearson 
examination. There is also the classification and categorization of ideas, so the topic must be well-organized to gain higher scores.

The acquisition and teaching of grammar have been a significant issue at the center of many second language acquisition research controversies. It becomes even more controversial when young learners are concerned (Uysal \& Bardakci, 2014).

For instance, students are given partial information about a grammar structure, making it seem more straightforward than it is, or in other words, students are 'led down the garden path.' Learners may also be provided with the rule without being told its exceptions. The reason for giving students only a partial explanation is that it is hypothesized that students are more likely to learn the exceptions to the rule if they are corrected at the moment. They make an overgeneralization error than if they are given a long list of exceptions to the rule to memorize in advance (Larsen-Freeman, 2015). Hence, it is suggested that rather than working on inducing or deducing grammatical rules, other learning instructions like input-based must be done for the learners to attend to some problematic grammatical form during input activities.

Moreover, learners know the correct grammar rules, for they have been corrected when they commit mistakes. However, according to Uysal and Bardakci (2014), error correction is unnecessary and even harmful as it may interfere with the natural acquisition process in which learners would subconsciously analyze the forms and eventually deduce the rules from the language input themselves.

In this regard, teachers need to reconsider their (traditional) methods, as these help them know what their teaching should focus on. Most educators especially persist in seeing grammar as a set of rules that govern proper form in the language (LarsenFreeman, 2015).

Despite having traditional methods that are still applicable in teaching grammar, considering the plausible idea of teaching it communicatively, in other words, how teachers can make of grammar teaching traditionally was considered as set of principles to apply to form correct sentences communicative, deserves close attention (BancoléMinaflinou, 2018).

Grammar teaching plays a vital role in the English language teaching field. Especially that grammar is not naturally acquired; instead, it is learned and instructed. Zhang (2009) emphasized that grammar operates at the sentence level and governs the syntax or word orders permissible. It also works at the sub sentence level to govern such things as number and person agreement between subject and verb. Some students may have a more analytical learning style to grammar learning than others, but if one hopes to use the English language accurately and fluently, they must receive grammar rules instruction. With this kind of complexity in learning and teaching, there is a need to focus on teaching grammar. This is supported by Altiner (2018), saying that teachers of English as Foreign Language (EFL) and English as Second Language (ESL) should be experts with these grammar structures and how they are applied, the specific areas where students get confused and find difficulty with, and the necessary teaching strategies to cater to these challenges. Hence, there is a need to study this area to have standard grammar teaching, specifically what to focus on. 


\section{Research Question:}

In the place of international examinations, what should be the focus in the teaching of grammar?

\section{METHODS}

This study followed a guideline for performing systematic literature reviews (SLR) proposed by Kitchenham (2010). A systematic literature review identifies, selects, and critically appraises research to answer a formulated question (Dewey \& Drahota, 2016). The systematic review should follow a clearly defined protocol or plan where some criteria are clearly stated before the review is conducted.

\subsection{Data Procedure}

First, the eligibility criteria prepared to facilitate the sifting of information collected. Table 1 illustrates the eligibility criteria used in this study.

\section{Table 1: Eligibility Criteria}

\begin{tabular}{|c|c|c|}
\hline Parameters & Inclusion Criteria & Exclusion Criteria \\
\hline Type of Research & $\begin{array}{lr}\text { Primary researches } \\
\text { published in peer- } \\
\text { reviewed } \\
\text { scientific papers }\end{array}$ & $\begin{array}{l}\text { Books reviews, opinion } \\
\text { pieces, literary reviews, } \\
\text { policy documents }\end{array}$ \\
\hline Results of the study & $\begin{array}{l}\text { Research articles or } \\
\text { scientific papers that dealt } \\
\text { with the teaching of } \\
\text { grammar specifically for } \\
\text { test takers of international } \\
\text { examinations }\end{array}$ & $\begin{array}{l}\text { Research articles or } \\
\text { scientific papers did not } \\
\text { discuss grammar teaching } \\
\text { challenges met by } \\
\text { teachers and practical } \\
\text { strategies employed for } \\
\text { learners aiming to pass } \\
\text { English international } \\
\text { tests. }\end{array}$ \\
\hline Language & $\begin{array}{l}\text { Research articles or } \\
\text { scientific papers that made } \\
\text { use of English as a medium } \\
\text { of writing }\end{array}$ & $\begin{array}{l}\text { Research articles or } \\
\text { scientific papers that did } \\
\text { not make use of English as } \\
\text { a medium of writing }\end{array}$ \\
\hline Database & $\begin{array}{l}\text { EBSCO, Google Scholar, } \\
\text { ERIC }\end{array}$ & $\begin{array}{l}\text { Databases not accessible } \\
\text { to the researcher }\end{array}$ \\
\hline
\end{tabular}




\begin{tabular}{l|l|lc}
\hline Time Frame & $\begin{array}{l}\text { Research articles or } \\
\text { scientific papers on }\end{array}$ & Research articles or \\
research writing published & scientific papers on \\
from 2010 & published before 2010 \\
\hline
\end{tabular}

Second, the eligibility criteria were applied in selecting articles to make certain that only the pertinent studies were utilized and no relevant studies were excluded. Initially, studies were not included if they meet one or more of the exclusion criteria.

Third, the studies related to the problem were collected and sifted using a critical evaluation method to include studies that meet some high quality or systematic standard (Slavins, 1987 as cited by Meline, 2006). The researcher identified the specific inclusion and exclusion criteria in obtaining the available information from the databases. The main criterion is that the study involves teaching grammar specifically in the place of international examinations.

Fourth, relevant findings from the selected studies were extracted. Then the findings were thematized based on shared ideas. Key concepts on the topic that appear repetitively in several studies signal being dominant concepts for the study.

Fifth, data were discussed and concluded.

\subsection{Treatment of Data}

A matrix was prepared to filter the necessary information from all the articles. Key concepts and salient information were culled. Then these were meticulously analysed in terms of the gaps and struggles of English teachers preparing learners for the international exams and the test-takers themselves, and the strategies helpful in teaching grammar. One author's information was disregarded, whereas common ideas were highlighted and utilized in the study.

The challenges and aspects that needed to be focused on in teaching grammar to international students identified by the authors were then discussed. Based on the data, the statements and concepts were associated with the authors who identified them, and then the related specific details were added. The explanation or rationale of the struggles encountered and what should be the focus in grammar teaching, when stated by the authors, were included to bring about a comprehensive presentation. All possible significant concepts culled from the studies were incorporated. The result shows a presentation of this study's primary goal, which was to teach grammar in response to the struggles and weaknesses articulated by the exam takers.

\section{FINDINGS AND DISCUSSION}

The present study's findings were outlined based on the research question: what aspects of grammar should be taught in place of English international examinations? With this, the following were discussed, namely: (1) syntactic variety, (2) parts of speech, (3) word choice, and (4) dialect variation. 


\subsection{Syntactic Variety}

\subsubsection{Sentence Patterns}

According to He (2016), good sentence patterns and vocabulary must be combined to make good writing. As defined, sentence patterns are the underlying skeletal structure of almost all the possible grammatical sentences (Kolln \& Funk, 2011 as cited by Charpentier-Jiménez, 2020). Also, it is said that ten patterns are commonly used in the English language. However, the main problem with this definition is that grammarians have not often agreed on the number of English patterns (Charpentier-Jiménez, 2020). It is explained by Kolln and Funk (2011) that the list of patterns that we know is not the only way to organize parts of the sentences (i.e., verb classes), especially that there are at least fifteen patterns.

Nevertheless, considering the study of Kolln and Func (2011) again, CharpentierJiménez (2020) summarized these ten (10) patterns:

"Pattern I. NP1 + V-be + ADV/TP": The musicians are here.

"Pattern II. NP1 + V-be + ADJ": The players were happy.

"Pattern III. NP1 + V-be + NP1": Alonso is a famous artist.

"Pattern IV. NP1 + LV + ADJ": They seem nice.

"Pattern V. NP1 + LV + NP1": The chairperson called off the meeting.

"Pattern VI. NP1 + V-int": The baby was sleeping.

"Pattern VII. NP1 + V-tr + NP2": The firefighters rescued the cat.

"Pattern VIII. NP1 + V-tr + NP2 + NP3": I sent flowers to Laura.

"Pattern IX. NP1 + V-tr + NP2 + ADJ": The jury found them guilty.

"Pattern X. NP1 + V-tr + NP2 + NP2": They elected her president.

Furthermore, He (2016) emphasized that students' English writing depends on sentence pattern learning and translation activities, and it is essential to integrate sentence pattern and translation exercises in English writing learning and instruction. Despite a wide range of literature on sentence pattern practice and translation drills undertaken both at home and abroad, no action study research on fundamental sentence pattern translation drills to improve English writing has ever been conducted yet. It implies that teachers need to observe these patterns by conducting action research as much as possible. Also, it is explained by the said author that the results of this action research shows that the basic sentence pattern translation drills are effective and of much help to students' English writing. Meanwhile, it enables them to enhance their reading skills; some of these reading materials are easier for them. Furthermore, translation drills on good sentences relevant to particular topics might significantly enrich the writing's content. This action research is linked to reflective practice, and the instructor, as the researcher, takes the lead in the writing class. The researcher investigates non-English majors' writing difficulties in English and is also one of the attendees, improving students' English writing.

Aside from conducting action research, as said by He (2016), it is also essential that the following questions be addressed about sentence patterns. Charpentier-Jiménez (2020) enumerated specific questions that need to be answered to modify teaching practices: Are these patterns strictly necessary to convey what students wanted? Do students use 
these structures because they are simpler? Is it possible for students to express the same idea using other verbs? How can instruction be improved so that students raise awareness and stop relying upon "be" verb patterns? By answering these questions, instructors can develop adequate strategies to determine which writing structures need more attention. The rew rite stage could be a phase student dedicate to finding all "be" verb patterns in their writing. During this part of the writing process, students would be asked to revise those sentences and replace "be" verbs with other peers and the instructor.

Interestingly, though these patterns have complexity and need to be learned formally, it is also suggested by Ismail and Shafie (2019) that this can be learned informally and through Social Networking Sites (SNS). In the details of the study, most of the respondents agreed that they learned English skills by saving English quotes and images posted on SNS, paying attention to the sentence patterns and accents while watching videos on SNS, and trying to understand news in the English language reading them on the SNS. Meanwhile, the method used the least was by posting videos on the SNS to improve the language. By employing these methods while engaged on the SNS, the students perceive that some of their English skills have improved: listening skills, vocabulary, and competence in reading and speaking.

\subsection{Parts of Speech}

Parts of speech are the groups of English words that fit into eight functional categories. These words make up sentences and are, therefore, the building blocks of language. Understanding how to use these building blocks lets test-takers master complex sentences and fancy vocabulary, but we may fall short if our necessary language skills are not there. Therefore, in English international examinations, nouns, pronouns, verbs, adjectives, adverbs, prepositions, conjunction, and interjection are fundamental aspects of grammar as the focus in teaching.

\subsubsection{Noun}

In learning the different parts of speech, it is common for English teachers to let the students underline the noun, encircle or box the verb. Alternatively, perhaps the students will write the correct pronoun that corresponds to the noun. However, with all of the drills on the different parts of speech, teachers still often hear students ask when and how they will be using these parts of speech in their future endeavors, not realizing that these have an essential role in writing. Thus, a sentence is made up of words; the sentence's meaning cannot be understood without any of it. Hence, it is impossible to decipher a subject unless implied that a noun is a person, place, thing, or idea.

Moreover, a predicate cannot be identified if it was not introduced that a verb describes an action or condition of being. The different parts of speech probably make any writing easier. Of the considerable number of parts of speech, nouns are maybe the most essential. A noun is a word that recognizes a man, creature, spot, thing or thought.

The pronoun emerged as a part of speech in the mid-15th century, according to Merriam-Webster Dictionary (2018), from the Latin word pronomen (pro meaning in place of and nomen name, noun), which is a derivative translation of Greek antonymia. 
The pronoun, according to Abia (2013), are words which are used in place of nouns to minimize unnecessary repetition. To put it differently, a pronoun is a grammatical object that is utilized to replace a noun or a noun group. One feature that makes pronouns a particular class of linguistic items is how they contribute to the implication of the sentences (or other constructions in which they occur). Pronouns can be singular or plural (I, me, he, she, you, it) (they, them, we, etc.). However, their functions are limited to acting as a stand-in for the subject or object of a sentence: The girl spent the weekend sewing the girl's dress in order to have enough time on Monday to make the necessary alterations. Without the use of pronouns, the above statement exemplifies how sloppy and repetitive writing may be. The statement can be cleared up as follows when applied effectively: The girl spent the weekend making her garment in order to have enough time on Monday to make changes to it.

As a result, each pronoun has an antecedent (noun that is being replaced): her (the girl), she (the girl), it (the girl) (the dress). From the sentence above, it is clear that pronouns make the reader understand the text better. Hence, without any confusion of who and what is being described. Moreover, pronoun-antecedent should also be observed. Thus, the pronoun antecedent is defined as the noun it refers back to. The antecedent is normally mentioned before the pronoun in the text, although it can sometimes appear after it in a phrase. (McCombes, 2019).

\subsubsection{Pronouns}

However, one of the difficulties in learning English is the pronouns. The main problem in learning pronouns is the use of pronouns itself. It is essential to use pronouns carefully to attain clarification and exactness of meaning in writing or speech. Pronouns are categorized as a subclass of nouns. The use of pronouns is more complex (Pratika, 2008). Hence, the rules of pronoun-antecedent must be observed.

\subsubsection{Verbs}

The third in the list on the parts of speech is Verbs. Verbs are imperative to any language development because they allow writers to start building sentences. A complete sentence is composed of a subject and a predicate. Moreover, a predicate cannot be identified if it is not introduced that a verb describes an action or state of being. Thus, without verbs, it would be impossible to construct a sentence, as a complete thought would contain one. Verbs are also crucial in that they are considered fundamentally crucial in learning many grammar rules and how we use them. A recent study (Hadley et al., 2016) showed that we could predict children who will have more advanced grammatical skills at 30 months by the size of their verb vocabularies at 24 months. Research says that the best way to target verbs is through play and exposure to real-life activities such as Simon Says.

\subsubsection{Adjectives}

In writing and speaking, we frequently use descriptive words to make our writing and speeches more vivid and visual. This is impossible to achieve without the use of adjectives. In Dahami's (2012) study, she defined an adjective as a word used to describe the noun. Moreover, according to the online Wikipedia Encyclopedia, the adjective is a 
word whose primary role is to modify a noun or pronoun, giving more information about the noun. They can never take determiners like nouns, but adjectives can take adverbs as modifiers. Different from the noun in English, the adjectives can never be used as a plural. The function of adjectives in English is to clarify the meaning of nouns to make them noticeable, but the adjectives limit their application. Thus, adjectives will significantly contribute to the reader's appreciation of one's work and describe one's characteristics. It also appeals to the reader's senses, making them see, hear, feel the things described.

In addition, adjectives are essential because they describe a noun (person, place, or thing), talk more about a noun (person, place, or thing), make sentences more interesting, and affect the meaning of sentences.

\subsubsection{Adverbs}

Adverbs can be used to modify sentences to give a general feeling about the information within them. Take a look at this example: "Interestingly, adverbs are not something many candidates feel confident about." The use of 'interestingly' at the start of the sentence tells us how the writer or speaker feels. Alternatively, if the writer or speaker found something to regret, they would have used it regrettably, or if they felt frustrated with adverbs, they would have used 'frustratingly.' Adverbs are super helpful when speaking to patients as they understand what is coming next. They can prepare them for good news, bad news, etc. it is then appropriate to learn the use of adverbs to master clarity as part of the band descriptors, especially in the writing skill.

\subsubsection{Prepositions}

Language experts often evaluate the learners' performance in writing skill through performance-based assessment tasks such as the constructed response in essay mode. Generally, using prepositions in proper context is a never-ending concern in the field of linguistics. Loke and Anthony (2013) asserts that correct use of prepositions is one of the most challenging tasks that English learners have to master. Relatively, Swan (1998) emphasizes that in teaching and learning English as a Foreign Language (TOEFL), learners tend to get confused in the proper usage of prepositions. To define, Castro (2013) simply states that prepositions are "words that show the connection between two words in a sentence."

Inevitably, learners may commit several errors while learning English as a foreign language. As cited earlier, errors in utilizing prepositions in English grammar can be considered as one of the major struggles of students in learning the target language. The outputs of students in their writing tasks prove that they definitely have difficulty in the application of correct prepositions. In another study conducted by Estevez, Gomez, and Gonzalez (2010) at the Universidad Industrial De Santander, it was revealed that the use of prepositions by the students of an upper-intermediate English course from the ELT program is indeed complicated and confusing. Out of 71 identified errors in the use of prepositions, quantitative findings showed that 13 , including - to, on, about, in, at, for, from, with, by, above, because of, into) were the most common. It was elucidated that the 
error committed by most of the test-takers was the misuse of prepositions which was present 30 different times. Meanwhile, the omission of prepositions appeared 25 different times, and the addition of prepositions occurred 16 different times.

\subsubsection{Conjunctions}

In terms of fluency and coherence, it refers to the ability to have a talk with continuous levels of normal continuity, effort, and rate. In addition, the way on how to link ideas is considered in coherence. Though, fluency focuses on the continuity and rate of speech. On the other hand, coherence focuses on the sequence of sentences, clear discussion, argument, and the use of cohesive devices. In highlight, conjunctions are also helpful as signposts to guide the reader (examiner) through the writing tasks and ensure that their essay is coherent and easy to follow. This is vital as it is an essential part of how writing is assessed.

One common problem is on connectors and conjunctions. This suggests EFL teachers and IELTS trainers to design a course catering to this learning aspect. Further, it is worthy to note that inappropriate word choices were commonly observed, hence, it is possible that language learners and IELTS candidates might not understand that memorizing vocabulary may not always be an effective strategy as words have lexical meanings and can fit in multiple contexts, each with a certain meaning.

The recent study of Seedhouse et al. (2014) shows characteristics of candidate discourse about the rates they received. The quantitative measures revealed that the increase in precision, exactness, and reliability is relative to the scores provided. Grammatical range and complexity got the lowest band of 5, however, it is surprising to note that band seven holders got higher scores in this area as compared to the band 8 candidates. It is then suggested that in any IELTS speaking test, a wide range of accessible speaking features can be maximized to target a specific goal. Hence, it indicates how conjunctions are integral in the teaching of grammar.

\subsubsection{Interjections}

In line with a communicative curriculum for English, it is claimed that communicative competence involves knowledge about when and how to display affectivity in talk-ininteraction (Reber, 2011). Typically, interjections have been described as a lexical means for expressions of emotion. Also, the sentence completion and reading comprehension questions that appear in the standardized exams require a good knowledge of various interjections. The problem here is that many interjections are in vogue, but only a few will be tested. The most commonly used interjections in standardized exams are: oh, alas, ouch, Godspeed, we aye, aww, hey, etc.

According to Goddard (2013), whether it is possible to pin down the meaning of any word - and, if so, to what level of precision - and even the nature of "meaning" itself remains controversial issues in linguistics and psycholinguistics. There are competing approaches and practices. For emotive interjections, the most common approach is functional labeling using emotion words, saying, for example, that Wow! and Yuck! Express surprise and disgust, respectively. Sometimes a modifier indicating strength or 
quality is added, for instance, intense surprise, mild disgust. Often several labels are strung together disjunctively and may be accompanied by an open-ended "etc.," for example, "astonishment, surprise, etc.," "disgust, derision, etc." Such characterizations, common in dictionaries, are open to the criticism that they are vague and only weakly predictive. Hence, interjections should be carefully taught as part of the learner's grammar learning.

Therefore, strengthen grammar when studying sentence structure. Visualizing the sentence structure shows how sentences may need revision; it also reminds the parts of speech and how they function in a sentence. Writing may improve if you master these elements, especially your understanding of proper syntax and diction, developing the other skills. In educating the learners, it is essential to teach these parts of speech in grammar teaching.

\subsection{Word Choice}

Based on the survey conducted by some OET Experts regarding some common mistakes made in the Writing sub-test, word choice is common errors encountered in their exam. The following instances are encountered: a. Using 'rule out' to mean 'confirm' means eliminating or excluding something impossible. However, sometimes people make the mistake of switching the meaning around. For example, the case notes say: 'pneumonia ruled out (X-ray).' Now, the letter written by the student reports: The patient has pneumonia. In the example given, the $X$-ray reveals the patient does not have pneumonia, i.e., the exact opposite of what the student wrote; b. Using 'complaint' instead of 'compliant,' this mistake might be because of a typo as the spelling of the two words is very similar. For example, "The case notes say medication-taking regularly as per instructions." The letter written by the student reports: "the patient is compliant with their medication." This sentence suggests that the patient is unhappy with their medication because of the misspelling. With the correct spelling, the sentence would explain that the patient is taking their medication correctly.

Moreover, words are only one component of communicative strategies, albeit a significant one, if not the most important for discussing treatment options, treatment goals, and means to reach those goals. However, words and phrases tend to become independent of their users over time. Subsequently, the article by Curtis, Sprung, and Azoulay reviews five phrases (in the English language) often used in communicating with their clients and family members and colleagues that potentially convey unintended negative messages or lead to confusion amongst those communicated with. At the end of the reviewing process, the article offers suitable alternatives or replacements, e.g., instead of stating that treatment(s) will not be escalated, there needs to be a decision made as to which treatment(s) should be continued, escalated or de-escalated -- and whether additional specific treatments are indicated. Similarly, a phrase like "care will be withheld or withdrawn" is false and unjust because an ICU team will not stop caring for a patient. However, the decision might be reached to withhold or withdraw life-sustaining treatments. Moreover, subsequently, comfort care will be rendered. 
Congruent with the recent studies mentioned above, the research of Dashti and Razmjoo (2020) emphasized that the result brought multiple types of errors base on the oral presentations that examined the lexical features, namely: LR1(wrong choice of word), LR2 (problems in collocations), LR3 (issues in the formation of words), and LR4 (order of words). The five examples below revealed these errors taken from the five quotes.

Example 1: ..." why can you ignite your hands" ... (MAR024)
Example 2: "I think this journey was so sunshine" (FDN034)
Example 3: ... "clothes he uses [s] in the game" (MKR014)
Example 4: .. "they are not supposed to make noise too much" (FAE01)
Example 5: ... some of them like to hard work (MMK019)

The first example highlights the choice of word error [PS1] ("ignite"), which triggered the examiner's ability to comprehend the problem. Meanwhile the second type of error shares the same features with the first one. It's complicated to comprehend what the candidates are trying to express by using the word "sunshine" as an adjective. The number 3 example reflects wrong collocation. The word "clothes," under the central boundaries of the test, it must include the verb "to wear." The last example is the error in the word-formation. The candidate should have said, "supposed" (past participle form). The word order is an evident issue in the last example. The word order is an evident issue present in the quote.

Word choice is apparent in these takers; thus, it should matter in grammar learning. Choice of word is among the integral portion of any written product particularly in narrating an idea. The selection of appropriate words is beneficial since it elevates the impact of the language to the audience.

\subsection{Dialectic Variation}

According to Shareah et al. (2015), language diversity is evident among all the languages around the world. And the diversity of these languages can never be considered a language defect. Human language is systematically governed by a certain rule which brings us to a vast amount of creativity which is one of the essential characteristics of language.

Moreover, the existence of dialects or varieties in every language is evident. When a specific spoken language is utilized according to the users is considered a dialect, the speaker's geographical background usually determines dialects. In definition, a dialect is a unique system of language associated with several social, regional, group and ethnic. Its linguistic characteristics, grammar, vocabulary and pronunciation makes it differ from other variations of language. (Shareah et al., 2015). For instance, in the northern part of the Philippines, most people use Ilocano as their language, mainly that some places use it as their lingua franca. Like the English language, Ilocano also has varieties according to geographical areas like - Ilocano dialect in the Cordillera Region, Ilocos Region, and the Southern part of Luzon. As said, these dialects are characterized by their lexical 
properties, syntactical features and phonological features. However, in the areas of speech, an emerging problem exists in terms of the community's behavior towards the speakers of these dialects. The speech community creates labels to rank these various forms of spoken language which creates an impression of stigmatizing or elevating the speaker. In other words, their ability to pronounce and select words base on their background knowledge of the language defines his rank on how well and good the person is. (Shareah et al., 2015). That is why in education, it is also affected - on how teachers teach and learners learn.

Language teachers generally perceive some sociolinguistic concepts regarding their mother tongue and the language they teach as part of their profession (Üresin \& Karakaş, 2019). There is a close correlation between the development levels of societies and education systems and educators' qualifications. One of the main characteristics of qualified teachers, who play an essential role in the emergence of modern societies, is their ability to use the language correctly and effectively. Because in education, the method of transferring information is as essential as the knowledge itself (Bozkırlı \& Er, 2020).

Nevertheless, in one of the studies of Bozkurlı and Er (2020) to prospective teachers in Turkey's different cities, they pointed out that they did not realize if the use of local dialects in teaching is correct. Most prospective teachers stated that they felt comfortable using their local dialects because they could speak freely and out of sincerity; however, teachers who expressed that they were not comfortable using local dialects explained it to be inappropriate for their occupation for the social environment. Similarly, the study of Üresin and Karakaş (2019) pointed out negativity when teaching different dialects and varieties in schools because most teachers believe that teaching these deviant forms would adversely affect the standard language and the quality of the language teaching process. Therefore, there is enough evidence to advance the claim that teachers respect regional and non-standard varieties and dialects in principle. However, such respect does not translate into practices, especially in including these varieties and dialects in language teaching milieus.

Since people have a lot of reasons as to why and how individuals intended to use the language differently according to their social context including the how and why they speak differently. It is studied that there must be a standard set in any unregulated spoken language (dialect) The standard language is defined when the community of speakers uses a language variety in their day-to-day public discussions. Like the English language, it is suggested that specific rules must be made and will undergo consensus. Specifically, a variety of language becomes a norm through the process of standardization to which this systematically categorizes their description in grammar, inclusion in the dictionaries and insertion in the references (Shareah et al., 2015). With this, it is easy to teach grammar to the students. Besides, Üresin and Karakaş (2019) attested that standard language is perceived as more effective in terms of intelligibility.

Hence, it is evident to say that variation should be recognized and acknowledged as a neutral operation. For this reason, linguists still cannot prove that the non-standard language remains less relevant in communicating versus the standard language. In 
conclusion, variation does not define the worth of a language nor its rank. (Shareah et al., 2015). Instead, setting a standard in every dialect will make teaching easy.

\section{CONCLUSION}

The various English standard tests have been the primary instrument in measuring the competence of test-takers in English around the globe. With all the presented set of knowledge concerning the focus of teachers in teaching grammar. The research highlights four main parts that calls teachers to consider, namely syntactic grammar, parts of speech, word choice, and dialect variation.

This implies the need to consider content knowledge development on the test takers as a necessary aspect of their English language growth. This calls the teachers to:

a) employ teaching strategies to successfully deliver the competencies that the learners need to develop to satisfy the set standards demanded in the various English standardized tests.

b) examine the curriculum plan in order to synchronize the contents and concepts of English. This means relevance that connects their formal classroom experience to the expectations of the standardized test in English.

c) expand their learning opportunities which will give test takers a new experience from their formal classroom experience. This provides them stimulations that deepen their theory and practice as a result of their engagements. Tutorials, online quizzes, English applications, listening to speaking, and other drills and games separate paper and pencil tasks.

d) feedback, provide immediate learning feedback to the errors committed by test takers. The confrontations of these mistakes will result in selfawareness. This gives them the opportunity to determine the parts they need to address.

Teachers will have to revisit the practices and approaches they employed in the teaching-learning process of English in general and review all existing English criteria and tools that quantify their content knowledge. At this point, we can strategically address the issues and gaps of grammar.

\section{References}

Abia, S. (2013). Introducing modern english structure. Lagos: Anrison Printers.

Altiner, C. (2018). Teaching of focus structures in english. Journal of Education and Training Studies, 6 (11).

Bancolé-Minaflinou, E. (2018). Exploring the teaching of communicative grammar in efl classes in benin to promote language use in cba context. World Journal of Education, $8(6)$.

Bozkırlı, K. C. \& Er, O. (2020). The views of prospective teachers concerning the use of local dialect. European Journal of Education Studies, 7(10).

Castro, M. (2013). An analysis of prepositional errors of college students. In Proceedings of the 3rd International Conference on Foreign Language Learning and Teaching, 97-108. 
Charpentier-Jiménez, W. (2020). Quantifying sentence variety in english learners. Revista Electrónica Educare, 24 (3), 1-15. DOI: https:/ / doi.org/10.15359/ree.24-3.26

Curtis J. R., Sprung, C. L., \& Azoulay E. (2014). The importance of word choice in the care of critically ill patients and their families. Intensive Care Med, 40(4), 606-8.

Dahami, Y. (2012). Adjectives and their difficulties in english and arabic: A comparative study. Sana'a University Journal of Education and Psychological Sciences, 9.

Dashti, L. \& Razmjoo, S. A. (2020). An examination of ielts candidates' performances at different band scores of the speaking test: A quantitative and qualitative analysis. Cogent Eduation, 7 (1).

Dewey, A. \& Drahota, A. (2016). Introduction to systematic reviews: Online learning module Cochrane training. https://training.cochrane.org/interactivelearning/ module-1-introduction-conducting- systematic-reviews.

Estevez, V. C., Gomez, C., \& Gonzalez, J. (2010). Identification of the errors regarding prepositions usage in students of the upper intermediate english course from the elt program at universidad industrial de santander. Research Project. http:/ / noesis.uis.edu.co/handle/123456789/36298

Goddard, C. (2013). Interjections and emotion (with particular reference to "surprise" and "disgust"). International Society for Research on Emotion, 6 (1), 53-63. https:/ / doi.org/10.1177/1754073913491843

Hadley, P.A., Rispoli, M., \& Hsu, N. (2016). Toddlers verb lexicon diversity and grammatical. Language, Speech, and Hearing Services in Schools, 47, 44-58.

Hawes, K. (2018). How important is english grammar for your toefl and ielts?. https:/ / www.prepadviser.com/admissions-tests/important-is-englishgrammar-your-toefl-ielts-scores.

He, X. (2016). An action research on improving non-english majors' english writing by basic sentence pattern translation drills. English Language Teaching, 9 (1), 142-147.

Ismail, I. \& Shafie, N. (2019). English informal language learning through social networking sites among malaysian university students. 211-225. Asian Journal of University Education, 15 (3), 211-225.

Kitchenham, B. (2010). Systematic literature reviews in software engineering - A tertiary study. Journal Information and Software Technology. https://dl.acm.org/ citation.cfm?id=1808650

Kolln, M., \& Funk, R. (2011). Understanding english grammar (9th ed.). Longman.

Larsen-Freeman, D. (2015). Research into practice: Grammar learning and teaching. Lang Teach. Cambridge University Press, 48 (2), 263-280. DOI: 10.1017/ S0261444814000408.

Loke, D. L., Ali, J., \& Anthony, N. (2013). A corpus based study on the use of preposition of time 'on' and 'at' in argumentative essays of form 4 and form 5 malaysian students. English Language Teaching, 6 (9), 128. http://dx.doi.org/10.5539/ elt.v6n9p128

Meline, T. (2006). Selecting studies for systematic review: Inclusion and exclusion criteria. Contemporary Issues in Communication Science and Disorders, 33, 21-27. https://doi.org/10.1044/cicsd_33_S_21 
Merriam, G., \& Merriam, C. (2018). Merriam-webster dictionary. Springfield, Massachusetts: Merriam-Webster, Inc.

Nordquist, R. (2020). Defining grammar. ThoughtCo. https://www.thoughtco.com/ what-is-grammar-p2-1689675

Parkhurst, C. C. (1963). English for business (4th ed). Prentice-Hall, 139.

Pearson Education. (2019). Pte academic: Score guide for institutions - version 3. Pearson Education Ltd. https:// pearsonpte.com/wp- content/uploads/2019/10/ScoreGuide-for-institutions-Final-V3-20191030.pdf

Pratika, L. (2008). A descriptive study of teaching pronouns to the seven year students. http:/ / eprints.ums.ac.id/1120/1/A320040189.pdf

Reber, E. (2011). Interjections in the efl classroom: Teaching sounds and sequences. ELT Journal, 65 (4), 365-375. https:// doi.org/10.1093/elt/ccq070

Seedhouse, P., Harris, A., Naeb, R., \& Ustunel, E. (2014). The relationship between speaking features and band descriptors: A mixed methods study. IELTS Research Reports, 1-30. www.ielts.org/researchers.

Shareah, M., Mudhsh, B., \& AL-Takhayinh, A. (2015). An overview on dialectal variation. International. Journal of Scientific and Research Publications, 5 (6).

Tunaz, M., Muyan, E., \& Muratoglu, N. (2016). A corpus-based study on the preposition error types in turkish efl learners essays 1. International Peer-Reviewed Journal of Humanities and Academic Scinence.

Üresin, F. \& Karakaş, A. (2019). Investigation of turkish efl teachers' views about standard languages: Dialects and language varieties through the lenses of english and turkish. The Literacy Trek, 5 (2).

Uysal, H. \& Bardakci, M. (2014). Teacher beliefs and practices of grammar teaching: focusing on meaning, form, or forms? South African Journal of Education, 34(1), 116.

Vidaković, I. and Khalifa, H. (2013). Stakeholders' perceptions of the Occupational English Test (OET): An exploratory study. https:// prod-wpcontent.occupationalenglishtest.org/resources/uploads/2018/05/31235107/Vid akovic-and-Khalifa-2013-Stakeholders-Perceptions-Research-Notes-54.pdf

Zhang, J. (2009). Necessity of grammar teaching. International Education Studies, 2 (2), 184187. 